\title{
Perspectivas de controle de doenças transmitidas por vetores no Brasil
}

\author{
Perspectives of vector borne diseases control \\ in Brazil
}

\author{
Pedro Luiz Tauil ${ }^{1}$
}

\begin{abstract}
RESUMO
A análise do controle de doenças transmitidas por vetores no Brasil necessita considerar três aspectos: a urbanização da população, a transformação do caráter eminentemente rural dessas doenças em concomitante transmissão urbana ou periurbana e a descentralização do controle para municípios. A imensa maioria da população está vivendo nas cidades. Algumas doenças passaram a ser transmitidas em áreas peri-urbanas ou urbanas, graças à emergência ou re-emergência de seus vetores nessas áreas, como dengue, leishmaniose visceral e malária. Há dificuldades para o controle: as atividades em áreas rurais são operacionalmente mais efetivas, pois atingem coberturas mais elevadas; são mais bem aceitas pela população do que as exercidas em áreas urbanas. A descentralização do controle para os estados e municípios está em implementação e há também dificuldades, pois o controle vetorial não fazia parte da prática desses entes federativos. Para um controle mais efetivo, há necessidade de determinação política, ações multi-setoriais e uso racional de inseticida.
\end{abstract}

Palavras-chaves: Doenças vetoriais. Controle. Brasil. Perspectivas.

\begin{abstract}
The analysis of vector borne disease control in Brazil should consider three aspects: the urbanization of the population, change from a rural pattern to concomitant urban or peri-urban transmission and decentralization of control to municipalities. The great majority of the population now lives in urban areas. Some diseases are being transmitted in urban areas, due to the emergence or reemergence of their vectors, such as dengue, malaria and visceral leishmaniasis. Difficulties in control occur, as it is easier to apply control measures in rural areas, because there is more population adherence than in urban areas and so the coverage is higher and disease control is better. The decentralization of control activities to states and municipalities is being implemented and difficulties occur as these levels of government have insufficient accumulated experience in control. For more effective control, political commitment, multi-sector articulation and rational use of insecticide are required.
\end{abstract}

Key-words: Vector borne diseases. Control. Brazil. Perspectives.

Atualmente, no Brasil, as principais doenças vetoriais (doenças metaxênicas) sujeitas a controle são: dengue, malária, leishmanioses, doença de Chagas, febre amarela, esquistossomose, filarioses (bancroftose e oncocercose), peste e febre do Oeste do Nilo. Os programas mais importantes, pelo volume de recursos que movimentam, são o de controle da malária e do dengue. Medidas de controle vetorial não são utilizadas em todos os programas de controle de doenças transmitidas por vetores, mas apenas nos programas de controle do dengue e na prevenção da febre amarela urbana, da malária, da leishmaniose visceral e, eventualmente, da leishmaniose tegumentar americana, da peste e da doença de Chagas. No controle da febre amarela silvestre, das filarioses e na prevenção da febre do Oeste do Nilo não se trabalha com controle vetorial. Na esquistossomose, está praticamente abandonada a atividade moluscicida ${ }^{1}$.

\footnotetext{
1. Área de Medicina Social da Faculdade de Medicina da Universidade de Brasília, Brasília, DF.

Endereço para correspondência: Prof. Pedro Luiz Tauil. Núcleo de Medicina Tropical/UnB. Campus Darcy Ribeiro, Caixa Postal 4517, 70904-970 Brasília, DF. Tel: $55613273-5008$

e-mail: pltauil@unb.br

Recebido para publicação em 06/11/05

Aceito em 30/3/2006
} 
No passado, as doenças vetoriais eram fundamentalmente rurais, com algumas exceções, como a febre amarela urbana $\mathrm{e}$ a peste bubônica. A febre amarela urbana foi eliminada do Brasil em 1942, por meio de medidas de combate ao seu vetor urbano, o mosquito Aedes aegypti, (eliminado do país em 1955) e vacinação da população a partir de $1937^{2}$. A peste bubônica, no início do século XX, existia em áreas urbanas portuárias, sendo combatida por meio de medidas de desratização e anti-ratização.

Na análise das perspectivas atuais de controle das doenças vetoriais no Brasil, é importante considerar três aspectos: a urbanização da população, a transformação do caráter eminentemente rural dessas doenças em concomitante transmissão urbana ou peri-urbana e a descentralização das atividades do seu controle para municípios.

Mais de $80 \%$ da população brasileira, em média, vive hoje em área urbana, concentrada, particularmente, em grandes e médias Cidades. Manaus, capital da maior unidade da federação, concentra mais de $50 \%$ da população do Estado do Amazonas. Não só a população está concentrada em áreas urbanas, como esse processo ocorreu de forma tão rápida e intensa nos últimos 30 a 40 anos, que boa parte (cerca de 20\%) dos moradores urbanos vive em condições precárias de habitação e saneamento, em favelas, mocambos, invasões e cortiços.

Algumas doenças metaxênicas passaram a ser naturalmente transmitidas em áreas peri-urbanas ou urbanas, graças à emergência ou re-emergência de seus vetores nessas áreas. 0 dengue, a leishmaniose visceral e a malária são exemplos clássicos. E ainda existe o risco da re-urbanização da febre amarela silvestre. Sem dúvida, estes dois fenômenos, intimamente associados, trouxeram dificuldades para 0 controle das doenças vetoriais, pois as atividades de controle executadas em áreas rurais são operacionalmente mais efetivas, atingindo coberturas mais elevadas e sendo muito mais bem aceitas pela população do que as exercidas em áreas urbanas.

A descentralização da execução das ações de controle de vetores, em processo de implementação no Brasil, gerou a necessidade de incorporação, nas responsabilidades de saúde de estados e municípios, atividades exercidas junto aos locais de habitação e de trabalho da população, atividades estas que não pertenciam ao acervo tradicional da imensa maioria dos estados e municípios, como já o eram as atividades de assistência médica. 0 recrutamento de pessoal, sua capacitação, supervisão e controle para exercício de atividades complexas de campo, como a identificação de medidas antivetoriais adequadas as diferentes realidades locais e sua aplicação, têm ultrapassado as capacidades da grande maioria dos municípios, principalmente dos de pequeno porte. Associa-se a isso o fato de que limitações orçamentárias e financeiras têm dificultado a criação de carreiras profissionais, razoavelmente remuneradas, para manter o pessoal contratado, em geral com precárias relações trabalhistas, em atividade por tempo suficiente para aquisição de experiência de trabalho de campo.

Esses aspectos têm trazido um grande desafio para a saúde pública do país. Diferentes modelos de controle têm sido considerados e muitas estratégias têm sido questionadas e modificadas.
Os problemas gerais de controle de doenças vetoriais devem ser considerados ao lado dos problemas específicos para cada uma das doenças.

0 controle do dengue é um enorme desafio no Brasil e no mundo. É a principal doença re-emergente e mais de dois e meio bilhões de pessoas na Ásia, África e nas Américas correm, atualmente, o risco de adquiri-la ${ }^{3}$. 0 único elo vulnerável de sua cadeia de transmissão, com os recursos científicos e tecnológicos hoje disponíveis, é o vetor. Não se dispõe de tratamento etiológico e nem de uma vacina eficaz. 0 isolamento dos portadores do vírus é uma medida inefetiva, pois a grande maioria dos casos é assintomática ou oligossintomática, não permitindo sua identificação oportuna. 0 combate ao principal vetor do dengue, o mosquito Aedes aegypti, consiste em medidas contra as larvas e contra os mosquitos adultos. Os seus criadouros principais são produzidos pelos seres humanos, pois consistem em reservatórios artificiais de água. 0 programa de controle busca utilizar o menos possível drogas antilarvárias e inseticidas, valorizando a eliminação mecânica dos criadouros, quando possível. 0 mosquito adulto já apresenta resistência aos inseticidas organoclorados e organofosforados e está iniciando resistência aos piretróides. As larvas, igualmente já manifestam resistência incipiente ao produto organofosforado atualmente disponível. A aplicação espacial de inseticida, em ultrabaixo-volume, deve ser reservada para situações especialíssimas de surtos epidêmicos, tendo em vista sua baixa eficácia, danos ao meio ambiente e custo elevado. A eliminação de criadouros para redução da densidade de infestação e conseqüente redução da transmissão da doença é de natureza multi-setorial, uma vez que depende de melhoria do abastecimento de água, da coleta regular do lixo, das condições de moradia e da educação da populaçãó . Não há no mundo, atualmente, país que tenha eliminado a transmissão do dengue, após sua re-emergência na metade do século passado. 0 mosquito Aedes aegypti apresenta uma facilidade enorme de adaptação a diversas, e até primitivamente adversas, condições ambientais. No entanto, outras atividades de controle da doença, como a redução de sua letalidade, por meio de uma assistência médica oportuna e adequada e a redução das dimensões das epidemias, por meio de uma vigilância ambiental e epidemiológica efetivas, podem e devem ser perseguidas, pois se mostram exeqüíveis. Provavelmente, o desenvolvimento de uma vacina preventiva eficaz seja 0 grande diferencial para modificar favoravelmente a perspectiva de controle do dengue ${ }^{4}$.

A malária é ainda um dos maiores problemas de saúde pública no Brasil e no mundo. Ocorrendo, nos dias de hoje, principalmente, na África, Sudeste Asiático e na Região Amazônica da América do Sul, sua incidência anual é estimada em 300 milhões de casos, sendo $80 \%$ em países africanos situados ao sul do Deserto do Saara. Foi objeto de uma campanha mundial pela sua erradicação, na metade do século passado, a partir da aplicação de um inseticida de grande eficácia contra os mosquitos vetores do gênero Anopheles, de aplicação em superfícies e de efeito residual prolongado: o DDT. 0 resultado foi sua eliminação em países desenvolvidos e áreas desenvolvidas 
de países subdesenvolvidos. Porém, onde as populações vivem em condição precária de habitação e trabalho, e existem condições ecológicas favoráveis à proliferação dos vetores, não se conseguiu a redução de sua transmissão. Algumas espécies vetoras desenvolveram resistência ao DDT e a outros grupos químicos de inseticida. Porém, outros fatores se somam a este para explicar o insucesso da campanha em diferentes países tropicais e subtropicais. A sua determinação multi-setorial exige também ações multi-setoriais, envolvendo as políticas de colonização e reforma agrária e de meio ambiente. Exige ainda uma valorização política, pois atinge, em geral, população mais pobre e com menor poder de reivindicação. Desde 1992, a Organização Mundial da Saúde patrocina uma ênfase no diagnóstico e tratamento precoces para redução da mortalidade e gravidade dos casos. Esta estratégia reduz ainda as fontes de infecção para os mosquitos. O controle vetorial é agora seletivo, Isto é, depende das condições locais de transmissão: onde as casas não apresentam paredes completas, não se justifica a aplicação de inseticida nas suas paredes internas. Há situações em que se trabalha na redução dos criadouros, limpando-os de vegetação, drenando coleções de água, aterrando-as ou aplicando larvicidas biológicos. A borrifação das paredes internas dos domicílios ou a aplicação espacial de inseticida depende dos hábitos locais dos vetores e das características da transmissão local da malária. A abordagem multi-setorial e a participação da população são estratégias que podem tornar mais efetivas as medidas de controle de natureza biológica ${ }^{6}$.

A transmissão do calazar tem se urbanizado, na periferia de grandes e médias cidades. 0 seu controle envolve o diagnóstico e tratamento precoce dos casos detectados e controle dos insetos transmissores. A aplicação de inseticida no interior e no peridomicílio é geralmente dificultada pelo grande número de recusas por parte da população. Uma medida importante de controle, apesar de não ser consensual, é a identificação de cães infectados e seu sacrifício, pois seriam importantes reservatórios do calazar.

Uma atividade antivetorial extremamente exitosa foi 0 controle da transmissão vetorial da doença de Chagas, com a eliminação, em grande parte do território nacional, do seu principal vetor, o Triatoma infestans. Extremamente domiciliado em casas de pau-a-pique, foi vulnerável à ação de inseticida aplicado de forma seletiva em localidades e domicílios infestados. A perspectiva é a de manutenção de uma vigilância entomológica para detecção de eventual domiciliação de outras espécies transmissores. O sucesso do programa de controle da transmissão vetorial da doença de Chagas tem sido consolidado pelo esvaziamento da área rural do país ${ }^{1}$.
A prevenção da re-urbanização da transmissão da febre amarela tem sido efetiva no país pela redução da incidência da forma silvestre, por meio da vacinação, e do combate ao mosquito Aedes aegypti, seu principal vetor, que re-infestou o país de forma definitiva a partir de 1976. O controle da infestação desse mosquito é uma atividade desenvolvida no controle do dengue, buscando manter os índices de infestação os mais baixos possíveis.

A peste bubônica no Brasil distribui-se atualmente em bolsões geográficos e é combatida por medidas de antiratização e desratização, pois o seu vetor é a pulga do rato. Poucas medidas de aplicação de pulicidas são hoje em dia praticadas rotineiramente, somente quando se está diante de um surto da doença ${ }^{1}$.

Tendo em vista seu impacto negativo no meio ambiente e o risco de aparecimento de resistência dos vetores, o uso de inseticida tem sido bastante reduzido nos últimos anos. Por outro lado, quando é inevitável o seu uso, devem ser tomadas muitas precauções, entre elas, a capacitação de pessoal para sua aplicação, bem como o uso de equipamentos de proteção individual, como de roupas adequadas e, no caso de inseticidas organofosforados e carbamatos, monitoramento do nível da enzima acetilcolinesterase nos trabalhadores expostos.

Novos conhecimentos científicos e tecnológicos são necessários para que talvez um dia se possa pensar em controlar a transmissão de doenças vetoriais sem o uso de inseticidas nocivos à população humana e ao meio ambiente.

\section{REFERÊNCIAS BIBLIOGRÁFICAS}

1. Franco 0. A História da Febre Amarela no Brasil. Rio de Janeiro. Superintendência de Campanhas de Saúde Pública. Ministério da Saúde, Brasília, 1969.

2. Fundação Nacional de Saúde. Controle Seletivo de Vetores da Malária. Guia para o Nível Municipal. Ministério da Saúde, Brasília, 1999.

3. Gubler DJ. Dengue and dengue hemorrhagic fever: its history and resurgence as a global health problem. In: Gubler DJ, Kuno G (eds) Dengue and dengue and hemorrhagic fever. CAB International, New York, p. 1-22, 1997.

4. Kuno G. Review of the factors modulating dengue transmission. Epidemiologic Review 17: 321-335, 1995.

5. Ministério da Saúde. Secretaria de Vigilância em Saúde. Guia de Vigilância Epidemiológica. 6a edição, Brasília, 2005.

6. Tauil PL. Aspectos críticos do controle do dengue no Brasil. Cadernos de Saúde Pública 18: 867-871, 2002. 